Roger Williams University

DOCS@RWU

2012

\title{
Opportunities for Public Aquariums to Increase the Sustainability of the Aquatic Animal Trade
}

\author{
Michael F. Tlusty \\ New England Aquarium, USA \\ Andrew L. Rhyne \\ Roger Williams University, arhyne@rwu.edu \\ Les Kaufman \\ Boston University \\ Michael Hutchins \\ The Wildlife Society, Maryland \\ Gordon McGregor Reid \\ Chester Zoo, UK
}

See next page for additional authors

Follow this and additional works at: https://docs.rwu.edu/fcas_fp

Part of the Biology Commons

\section{Recommended Citation}

Tlusty, M., A.L. Rhyne, L. Kaufman, et al. 2013. "Opportunities for Public Aquariums to Increase the Sustainability of the Aquatic Animal Trade." Zoo Biology 32 (1).

This Article is brought to you for free and open access by the Arts and Sciences at DOCS@RWU. It has been accepted for inclusion in Arts \& Sciences Faculty Publications by an authorized administrator of DOCS@RWU. For more information, please contact mwu@rwu.edu. 
Authors

Michael F. Tlusty, Andrew L. Rhyne, Les Kaufman, Michael Hutchins, Gordon McGregor Reid, Chris Andrews, Paul Boyle, Jay Hemdal, Frazer McGilvray, and Scott Dowd 


\title{
COMMENTARY
}

\section{Opportunities for Public Aquariums to Increase the Sustainability of the Aquatic Animal Trade}

\author{
Michael F. Tlusty, ${ }^{1 *}$ Andrew L. Rhyne, ${ }^{1,2}$ Les Kaufman, ${ }^{3,4}$ Michael Hutchins, ${ }^{5}$ Gordon McGregor \\ Reid, ${ }^{6}$ Chris Andrews, ${ }^{7}$ Paul Boyle,${ }^{8}$ Jay Hemdal, ${ }^{9}$ Frazer McGilvray, ${ }^{4}$ and Scott Dowd ${ }^{1}$
}

\author{
${ }^{2}$ Roger Williams University, Bristol, Rhode Island \\ ${ }^{3}$ Boston University, Boston, Massachusetts \\ ${ }^{4}$ Conservation International, Arlington, Virginia \\ ${ }^{5}$ The Wildlife Society, Bethesda, Maryland \\ ${ }^{6}$ Chester Zoo, Upton-by-Chester, Chester, United Kingdom \\ ${ }^{7}$ California Academy of Sciences, San Francisco, California \\ ${ }^{8}$ Association of Zoos \& Aquariums, Silver Spring, Maryland \\ ${ }^{9}$ Toledo Zoo, Toledo, Ohio
}

${ }^{1}$ Prescott Marine Laboratory, New England Aquarium, Boston, Massachusetts

\begin{abstract}
The global aquatic pet trade encompasses a wide diversity of freshwater and marine organisms. While relying on a continual supply of healthy, vibrant aquatic animals, few sustainability initiatives exist within this sector. Public aquariums overlap this industry by acquiring many of the same species through the same sources. End users are also similar, as many aquarium visitors are home aquarists. Here we posit that this overlap with the pet trade gives aquariums significant opportunity to increase the sustainability of the trade in aquarium fishes and invertebrates. Improving the sustainability ethos and practices of the aquatic pet trade can carry a conservation benefit in terms of less waste, and protection of intact functioning ecosystems, at the same time as maintaining its economic and educational benefits and impacts. The relationship would also move forward the goal of public aquariums to advance aquatic conservation in a broad sense. For example, many public aquariums in North America have been instrumental in working with the seafood industry to enact positive change toward increased sustainability. The actions include being good consumers themselves, providing technical knowledge, and providing educational and outreach opportunities. These same opportunities exist for public aquariums to partner with the ornamental fish trade, which will serve to improve business, create new, more ethical and more dependable sources of aquatic animals for public aquariums, and perhaps most important, possibly transform the home aquarium industry from a threat, into a positive force for aquatic conservation. Zoo Biol. 32:1-12, 2013. (C) 2012 Wiley Periodicals, Inc.
\end{abstract}

Keywords: aquaculture; fisheries; ornamental fish hobby; pet trade; public aquarium; sustainability; tropical fish

\section{INTRODUCTION}

Zoos and aquariums (hereafter referred to as aquariums, as the focus of this discussion is on aquatic fishes and invertebrates) are important institutions for entertainment, education, and as drivers of in situ and ex situ conservation and basic and applied research on wildlife husbandry, nutrition, disease, physiology, and reproduction [Conde et al., 2011; Falk and Dierking, 2010; Gusset and Dick, 2010; Hutchins and Thompson, 2008; Miller et al., 2004]. The importance of conservation and research in these institutions is demonstrated by the $80 \%$ that have these terms in their mission statements [Wildes, 2003].
Public aquariums maintain diverse collections, holding 1,218 freshwater (E. Holbrook, Shedd Aquarium, personal communication) and 1,397 marine fish species [AZA, 2010]. While some public aquariums collect their own fishes, many fish obtained for these institutions are

"Correspondence to: Michael F. Tlusty, Prescott Marine Laboratory, New England Aquarium, 1 Central Wharf, Boston, MA 02110. E-mail: mtlusty@neaq.org

Received 16 August 2011; Revised 5 March 2012; Accepted 9 March 2012

DOI 10.1002/zoo.21019

Published online in 1 May 2012 Wiley Online Library (wileyonlinelibrary. com). 


\section{Tlusty et al.}

acquired from the same suppliers that provision the ornamental fish trade. This is evidenced by the $54.3 \%$ overlap between marine species on exhibit at public aquariums and those species imported into the United States [Rhyne et al. 2012]. Given the overlap in diversity and acquisition, public aquariums are inextricably linked to the ornamental fish trade [Andrews, 1990]. We postulate that this overlap provides an opportunity for public aquariums to engage in research and conservation on ornamental fishes. This can come in three ways: (1) through pure science initiatives on physiology and reproduction [Rhyne et al., 2009b], (2) through collaborative partnerships with the trade and hobbyists in order to provide guidance and incentive for developing sustainability in the trade, and to stimulate and promote a market for responsibly acquired aquarium fishes, and (3) by engaging the aquarium trade in programs and measures that benefit conservation programs in source countries where the native fauna representing aquarium biodiversity are threatened in the wild.

The ornamental fish pet trade is a large, biodiverse, global industry. There are an estimated 192 million individual fish imported into the United States yearly [Barker and Barker, 2009], with the number of marine species exceeding 1,800 [Rhyne et al 2012] and freshwater fish species exceeding 1,500 annually [Tamaru and Ako, 2000]. Domestic production of aquatic fish and invertebrates is significant. A total of 358 farms producing ornamental fishes in 41 states [USDA National Agricultural Statistics Service, 2005], and the state of Florida alone produces over 400 species of freshwater fishes for the pet industry. Florida also harvests over 9 million marine invertebrates each year [Rhyne et al., 2009a]. While data are scarce, imports to the United States comprise a larger proportion of the share of the trade, where for marine fish alone, 40 countries export over 11 million marine fish [Rhyne et al. 2012].

In North America, a number of public aquariums have been involved in efforts promoting sustainable seafood for more than a decade [Koldewey et al., 2009; Tlusty, 2012; Ward and Phillips, 2008]. There are currently around 20 independent certification programs for both wild-caught (e.g., Marine Stewardship Council) and aquaculture-produced (e.g., Global Aquaculture Alliance) fish and fish products [Jacquet and Pauly, 2007; Ward and Phillips, 2008]. There are also corporate-based advisory and consumer wallet card programs that promote continual improvement toward sustainability in all aspects of the seafood trade (e.g., Conservation Alliance for Seafood Solutions, http://www.solutionsforseafood.org/ forbusiness). This involvement by public aquariums is based on the tenet that seafood is an important protein source for humans, and that improving harvest and production methods will broadly benefit oceans and freshwater ecosystems over the long term. Public aquariums function as environmental non-governmental organizations to help promote environmental stewardship [Kuhlman and Farrington, 2010] of the seafood industry. However, given that public aquariums ex- ist to exhibit aquatic organisms for educational purposes, it is ironic that fish species destined for the plate currently have more sustainability efforts directed at them than do live fishes kept by private aquarists and public aquariums. This is partially a function of the massive biological and economic scales of food fisheries as compared to the relatively smaller scales for the home aquarium live animal trade. This may be a misleading metric, as it does not necessarily reflect the potential for home aquarists and their suppliers to indirectly or directly affect conservation in the wild. The broad and diverse nature of the ornamental fish trade, the fact that the aquarium hobby reaches a great many young people who are just developing their consumer and conservation habits, and the great emphasis on learning that is inherent to home aquarium keeping, all indicate that this sector should receive greater attention. Public aquariums could take advantage of the charisma of the ornamental species to engage visitors about ocean conservation [McClenachan et al., 2011], and although not widely adopted, such programs have been suggested for over two decades [Marliave et al., 1995]. Within the ornamental fish trade, there has been prior interest in sustainability as demonstrated through certification programs [Thoney et al., 2003]. However, the implementation and effectiveness of the Marine Aquarium Council was limited. Only a handful of producers were certified resulting in little resonance with consumers and retail chains [Alencastro, 2004]. A few companies have individual sustainability initiatives (see www.drsfostersmith. com/general.cfm?siteid=12\&gid=190), but these have not been combined with public relations campaigns, and thus are less known by consumers [Alencastro, 2004].

In this paper we address sustainability as it relates to the trade in live ornamental fishes and invertebrates. We also define the role public aquariums could have in driving efforts to implement sustainability initiatives for the hobby trade in these species. Finally, based on the recent decade of effort by public aquariums to promote seafood sustainability, we outline the many opportunities that these institutions have in working with the ornamental fish trade to increase sustainability (thus maintaining a high diversity of fishes for educational display purposes now and into the future), and to help shift the environmental impact of the ornamental fish trade from that of a threat to aquatic ecosystems (through over exploitation and exotic introductions) to an agent of positive change for conservation in the wild.

\section{WHAT IS SUSTAINABILITY IN THE ORNAMENTAL FISH TRADE?}

Sustainability is defined by the Brundtland Commission [World Commission On Environment and Development, 1987] as when resource extraction meets the needs of the present without compromising the needs of future generations. If this definition is strictly applied, the aquatic animal trade appears sustainable, as in wild fisheries, it is likely that the species being captured represent only a small proportion of the total population [e.g., cardinal tetra, Chao and 
Prang, 1997]. However, this narrow focus may fall short. If there is any inefficiency such as stress, disease, or high rates of mortality throughout the transport chain, and because of this, more specimens need to be landed, it can be argued that increased catches are potentially wasteful and not sustainable in a broad sense [Hueting and Reijnders, 2004]. If this species then arrives at retailers in a poor, stressed, or moribund state, the retailers may decide to not stock it because of excessive loss prior to sale. In this case, then home hobbyists cannot purchase representatives of this species, and there will be no continuing demand. While the fishery may have been sustainable in a narrow sense, the actions of the trade post-harvest rendered the fishery no longer solvent because of this lack of demand and thus the trade of this species could not be sustained. The above example elucidates the point that sustainability needs to be broadly evaluated over the entire trade chain, as all of the nodes of the chain are inextricably linked. The complexities of the trade networks [Amos and Claussen, 2009], make it important to take as broad a view as possible to determine overall sustainability.

Sustainability is not a single end point, but rather, it is a journey, and needs to be addressed through continual improvement at every step of the journey. Overall, the goal of an ornamental fish trade network should be to assure that in toto, the sustainability trajectory [Costa-Pierce, 2010] is continually increasing, with specific targets for achieving wild impact reduction milestones as well as broader conservation objectives. While it is important to assure that fish stocks and aquaculture operations [Tlusty, 2002; Tlusty, 2004] are maintained to promote sustainable objectives, there are a number of post-capture processes that may further affect sustainability [Tlusty et al., 2008; Tlusty and Lagueux, 2009]. Tools such as Life Cycle Analyses (LCAs) have been developed for a "cradle-to-grave" assessment, which can better account for these broader issues. A basic network for supplying wild species can be comprised of six or more nodes, including a fisher, an intermediary, an exporter, an importer, a retailer, and the end consumer [Chao and Prang, 1997]. It would be shortsighted to merely assess the fishery for sustainability while ignoring the actions of the subsequent five nodes.

\section{WHY IS SUSTAINABILITY IMPORTANT TO THE ORNAMENTAL FISH TRADE?}

Sustainability of the aquatic animal trade is important because it makes good business sense [Saunders et al., 1993]. The ornamental fish trade would benefit from adopting a philosophy of "enlightened self-interest" [Ikerd, 1999]. If sustainability is thought of in terms of efficiency, then increased efficiency can also lead to greater profits (less shrinkage, more fishes sold). However, this self-interest has larger benefits for the industry and ultimately biodiversity because, in the case of fisheries, less waste means fewer fishes are removed from the environment helping to maintain ecosystems in a more natural state. Species that suffer high mortality in captivity would benefit if either mortality was abated, or they were not removed from the wild in the first place. Self-interest can also benefit the well being of fishers, particularly in developing countries, provided they are paid more for higher quality animals. Ultimately, many of the animals collected for the ornamental fish trade have important ecological functions [Rhyne et al., 2009a], and thus sustainability initiatives can also positively affect the services that the ecosystem provides. This enlightened selfinterest provides benefits both to the ornamental fish trade, and the ecosystem in which it operates.

However, efficiency is not the only sustainability issue facing the ornamental fish trade. Additional challenges to the industry can be initiated by public campaigns, as well as significant concern regarding loss of biodiversity and the introduction of invasive species. Within the last decade, a number of primary [Tissot and Hallacher, 2003] and Internet articles [Wintner, 2010] have implicated the ornamental fish trade as having deleterious collection practices. Many of the detractors point out significant mortality within the industry, with estimates of the average as high as 50\% [Schmidt and Kunzmann, 2005], although complete loss of single shipments is also possible [Hemdal, 2009]. By adopting a sustainability platform, the industry can demonstrate a proactive stance in monitoring itself, and affecting positive change. Even in the face of significant mortality events, a platform setting forth a sustainability trajectory can identify the specific challenges, develop a plan to rectify it, and determine metrics that demonstrate positive change. This will not eliminate criticism of irresponsible acts. However, it provides a context to any challenge, and over time, can be used as a means in which to engage consumers and ultimately the detractors. Developing and reaching metric-based benchmarks (e.g., measures of survival or stress) will work to continually improve the industry.

Questions of impacts on aquatic biodiversity have been raised regarding the introduction of non-native species [Krishnakumar et al., 2009; Smith et al., 2009; Zajicek et al., 2009]. This issue recently materialized in the form of legislative action (HR 669), the Nonnative Wildlife Invasion Prevention Act, to eliminate the import and interstate transport of non-native species (except for goldfish and a number of terrestrial animals). While the invasive species issue is a large threat that has significant impacts beyond ornamental aquatic species, there is nothing about this industry that obliges it to be a contributor to the invasive species problem. Aquatic ornamental species are occasionally intentionally released as hobbyists decide that they no longer wish to hold an individual, as when a specimen outgrows its tank. Species can also accidentally escape farms, holding/import facilities, or hobbyist ponds, provided there are direct links to natural waterways [Courtenay and Stauffer, 1990]. These issues can be effectively controlled through commercial holding facilities adhering to best handling practices and biosecurity measures, and strong regulations should be in place and enforced. The proactive education of 
consumers at the point of purchase regarding the negative effects (invasive species introduction, food and space competition with native species, potential hybridization) through the intentional release of unwanted pets can minimize the probability of escapes. The number of species in the trade that easily outgrow their tanks is quite low and consumer education to reduce impulse buying or otherwise have hobbyists find themselves with a fish that has outgrown their tanks can dramatically reduce the rate of pet disposal into the wild. Here, the industry has taken such proactive steps through the development of the Habitatitude ${ }^{\mathrm{TM}}$ program (http://www.habitattitude.net/). This joint initiative (U.S. Fish and Wildlife Service, National Sea Grant College Program, and the Pet Industry Joint Advisory Council, www. pijac.org/) was developed with the purpose of preventing the intentional release of unwanted aquatic animals and plants [although bacteria and pathogens are often overlooked, Smith and Guégan, 2010]. While it is directly called for in the Habitatitude ${ }^{\mathrm{TM}}$ program, the key piece of the puzzle to minimize hobbyists releasing unwanted individuals remains for retailers to reestablish the practice of accepting unwanted specimens back at the point of sale. Several impediments are a hindrance to this program. First, retail stores must have a policy in place to always accept, with no questions asked, unwanted exotic pets, and perhaps a more difficult hurdle, are state laws preventing the transfer, trade, and gift of some species without proper licensing. Habitatitude ${ }^{\mathrm{TM}}$ also advises consumers with an unwanted fish to use public aquariums as a point of forfeiture (e.g., the animal donation form at Steinhart Aquarium, http://https://www.calacademy. org/academy/exhibits/aquarium/animal_donation _form/). However, public aquariums have not broadly supported this program as biosecurity issues and a lack of quarantine and holding space may prohibit participation.

Industry groups do have some internal code of conduct initiatives [Ploeg, 2010], yet they are largely unknown to the consumer. Consumer knowledge of sustainability, and corporate social responsibility is increasing in renewable resource industries (as seen in the seafood, timber, and coffee trades), and this may make it as an opportune time for the ornamental fish trade to adopt a sustainability platform. By doing so, it will help control for unintended negative consequences, and demonstrate a proactive approach to problem solving that can be translated into a positive industry message then broadening the market base by connecting with a new generation of aquatic home hobbyists. A failure to do so will most likely result in stricter regulations, as it is the taxpayers that are currently footing the bill to address particularly harmful exotics.

\section{THE STRENGTHS PUBLIC AQUARIUMS CAN BRING TO THE ORNAMENTAL FISH TRADE}

Within the renewable resource arena, environmental non-governmental organizations have worked cooperatively with industry, academia, and governments to improve the rigor of renewable resource sustainability practices. Often, the goal of this collaborative effort is to develop standards to assess sustainability criteria, and in this role, NGOs provide education, monitoring, social, and symbolic strengths [Boström and Hallström, 2010]. These provide a backbone of opportunities for public aquariums to effectively engage the aquatic animal trade in activities that promote both sustainability and conservation in the wild. The discussion that follows is by no means exhaustive. At the same time, while the list of opportunities is extensive, it is not implied that the full suite of suggested actions need to be tackled by each and every public aquarium. This is an a la carte list, and individual institutions can engage to the best of their ability.

\section{Educational Strength}

An important source of science education within the United States is the informal infrastructure associated with zoos and aquariums, museums, and nature programming [Falk and Dierking, 2010]. While a natural role of public aquariums is to inform its visitors about the diversity of aquatic life, recently, mission-driven programming has begun to systematically approach larger environmental issues. As an example, programming at the New England Aquarium (http://www.neaq.org) includes the thematic areas of global climate change, endangered species and habitats, conservation medicine, and fisheries and aquaculture. The educational role of NGOs, like public aquariums, should not be underestimated since recent evidence indicates that, in North America, most learning about science occurs outside of the classroom [Falk and Dierking, 2010].

Public aquariums have an opportunity to apply their educational strength and capabilities to the ornamental fish trade in a number of ways. Programmatically, displays of ornamental fishes can benefit institutions by being space efficient (small interesting animals), and by allowing presentation and education about challenges to aquatic habitats including the interdependency of aquatic and terrestrial habitat, the impact of habitat destruction on ecosystem services, challenges associated with invasive species, and biodiversity conservation. Ornamental fishes can also be presented in a manner demonstrating how the industry can be proactive in addressing the issues, with the potential to encourage visitors to embrace biodiversity and habitat conservation as important concepts (e.g., the Florida Aquarium's Aquarium Mania, http://www.tampabayaquarium.com/aquariumania. $\mathrm{htm})$. Public aquariums can educate visitors about the importance of fishes from various regions of the world where ornamental fisheries provide the economic framework for maintaining intact rural communities, particularly in developing countries. Elucidating and nurturing examples such as that demonstrated by the Rio Negro cardinal tetra fishery [Chao and Prang, 1997] highlights the broader socioeconomic benefits of an industry that is occasionally portrayed as being unsustainable [Wintner, 2010]. Participating 
in science-based market initiatives can yield outcomes such as environmental conservation, sustainable use of natural resources, and poverty alleviation. At the same time, the challenges the industry faces, including but not limited to invasive species and species that grow too large need to be exhibited as a cautionary tale [Marliave et al., 1995; Wabnitz et al., 2003] with constructive messaging regarding the necessary steps to prevent further negative impacts (see Section 5).

A further benefit of these educational messages is that they are likely to reach the world's future leaders in aquatic sciences, industry, law, higher education, and conservation. Although qualitative data are lacking, the authors of this paper demonstrate multiple careers that were cultivated in the early years through participation in the ornamental fish trade and keeping fishes as a hobby. This industry can act as a gateway toward science-, conservation-, and aquatic-based careers.

Thus in summary, the educational opportunities for public aquariums to engage with the ornamental fish trade include:

- Strategic implementation of an initiative that leads to vibrant, sustainable business practices at both the supply and demand ends of the industry, including infrastructure development and training.

- Using exhibits to foster positive examples of the ornamental fish trade.

- Educating the public about the potential impacts of the aquarium trade (invasive species, and those that grow too large) and the responsibility that hobbyists have in not contributing to the problem.

\section{Monitoring Strength}

Public aquariums possess a unique set of skills and assets that if directed toward a conservation objective within the aquarium fish trade, can be of great value to the industry. The global ornamental fish trade is data deficient for a number of reasons. Estimating the value of the industry is difficult because it crosses over to other hobbies (reptile, bird, and plant husbandry) and industries (aquaculture), and thus it cannot be isolated. In addition, import data are problematic given the way fishes are coded upon import [Rhyne et al., 2012; Smith et al., 2009]. Thus, while the number of marine fish species in the global trade have been estimated at 1,437 [Wabnitz et al., 2003], it was observed that just over 1,800 marine species were imported into the United States in 2005 [Rhyne et al., 2012]. Researchers at public aquariums can be involved in impartial oversight and data analysis of this high biodiversity trade.

Impartial oversight can carry into advisory capacity for retailers. On a technical level, public aquariums possess expertise and resources that can reduce waste and maximize market value of ornamental fishes. Such technical experience includes the minimization of trauma and stress related to capture, production, and transport as well as water quality management. Furthermore, public aquariums have experience and ability with health assessment and treatment not limited to nutrition, disease prevention, diagnosis and management, and the responsible and effective use of therapeutic agents. This includes providing oversight and statistical analysis of data derived from monitoring activities associated with shipping survival and performance. These ultimately can be worked into a formal plan for a multi-stakeholder derived best practices manual, an eco-label or a fair trade designation.

Public aquariums have a great deal of knowledge in the reproductive habits of the species on display [Thoney et al., 2003]. This knowledge can be cooperatively linked to universities and commercial producers, along the vein of the Rising Tide Conservation (http://www.risingtideconservation.org) program, to advance rearing knowledge skills and ability with a desired end goal to enact in situ conservation efforts [Hutchins and Thompson, 2008]. Public aquariums also have knowledge, skill, and ability of rearing and breeding species that are known not to thrive in the ornamental trade because they grow too large, are too delicate, or have specific and difficult-to-meet food requirements. A further expertise is in the design of secure breeding and holding facilities, which could reduce the risk of unwanted exotic species introductions - an issue that ornamental fish farmers want to avoid at all costs. This knowledge can provide for new methods and practices that may be adopted initially by the more advanced hobbyists and breeders, and honed to meet a more general audience. To date, however, there are few examples of where these parallel, aquarium fish-based industries have engaged in substantive exchange.

Thus in summary, the technical and monitoring opportunities for public aquariums to engage with the ornamental fish trade include:

- monitor trends in the trade of this high biodiversity industry,

- participation in a multi-stakeholder process to formulate best industry protocols and standards, and the development of monitoring programs to assure industry best practices are upheld,

- scientifically document the entire life cycle of species that are long-lived, large, rare in the trade, or with unusual habitat or food requirements, and

- a source of novel broodstock.

\section{Social Strength}

Social strength involves the access to "social capital" via networks and alliances [Boström and Hallström, 2010]. The keeping of ornamental fishes is one of the most popular hobbies in the United States, and can be greatly affected through social influences. For example, the release of the movie Finding Nemo (Pixar, Emeryville, CA) increased the sale of clownfish produced via domestic aquaculture by 


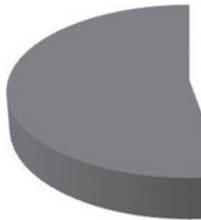

Yes

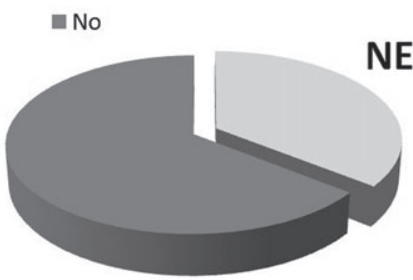

Copley

NEAQ

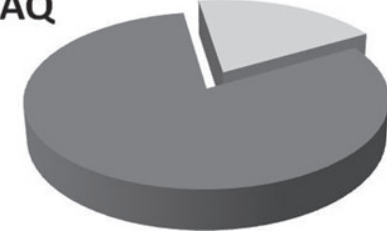

Fig. 1. Survey results from visitors at the New England Aquarium (bottom) and a Copley shopping district (top) when asked if they have ever (left) or currently own a fish tank (right).

$25 \%$ compared to one year prior to the film's release [McClenachan et al., 2011; Prosek, 2010]. Aquarium visitors, while often seeking entertainment, have a stronger draw to fishes and aquatic life than the general public. Within Boston, a survey was conducted at both the New England Aquarium (http://www.neaq.org), and 2 miles away at the Copley Square shopping district. Visitors at each location (n $=78$ and 80 , respectively) were randomly approached by interviewers wearing a New England Aquarium uniform shirt and were asked a series of questions. The questions assessed the respondents' past and current fish keeping status, as well as their future proclivity toward keeping fish. The three questions included: Have you ever had a fish tank? (yes/no), Do you have a fish tank now? (yes/no), and for those that answered no to the second question, How likely are you to get one in the future? (no, low chance, high chance, yes). The answers differed significantly depending on the location of the survey (Figs. 1 and 2). Respondents at the aquarium were nearly twice as likely to answer each of these questions in the affirmative. The widest disparity was that nearly $50 \%$ of the respondents at Copley Square indicated no interest in ever having a fish tank in the future, while that number was less than $20 \%$ at the Aquarium (Fig. 2).

Because of this interest, public aquariums can use social networks derived from the base of visitors that arrives daily to engage in messaging about aquarium sustainability. This can occur through educational activities (see Section 4.1), or conveying monitoring efforts (see Section 4.2). The social capital can be implemented by linking exhibits [Marliave et al., 1995] to messages of how the fish were procured for exhibit, and decisions to consider when buying sustainable fish for the home. The variety of social media that is currently available to public zoos and aquariums can be tapped for this purpose.

Thus in summary, the social opportunities for public aquariums to engage with the ornamental fish trade include:
- Helping to develop market-based initiatives that link retailers to sustainable fisheries projects.

- Creating social media campaigns to make visitors aware of best options for purchasing ornamental fish for the home.

\section{Symbolic Strength}

Trusted NGOs, such as public aquariums, can lend credence to a process (such as standards setting), or when goals are not upheld, they may also walk away in a demonstration of protest [Boström and Hallström, 2010]. When discussing the keeping and display of live animals, there is also the symbolism in the messaging of how animals are collected. There is much discussion within zoo and aquarium professional societies [Penning et al., 2009] about how to sustain captive populations [Thoney et al., 2003]. The concern is that since global aquatic biodiversity is significantly threatened [Helfman, 2007], the continued collection of species from the wild cannot continue as currently practiced [Conway, 2010]. This is where public aquariums need to work to balance their collection of animals procured through wild and aquacultured sources, and this idea will be covered in detail in the next section. But from a symbolic standpoint, public aquariums have the opportunity to enact broad based cooperative strategies to help maintain rare and endangered species [Raven, 2004; Thoney et al., 2003]. They should make sure that they are also contributing to field conservation efforts [Hutchins and Conway, 1995] and that intact natural ecosystems and their services continue to exist with extant native species, or where species are imperiled, that such areas are preserved into which captive bred individuals can be restocked.

As discussed previously, standards-based efforts have not been adequately developed, while individual company efforts are virtually invisible to consumers. Furthermore, these individual company efforts to improve acquisition are not currently used by the average consumer to differentiate companies providing ornamental fishes with respect to sustainability. What remains is that while some of the industry is "doing it right," the marine ornamental fish trade as a whole still has a number of deficiencies to be rectified [Amos and Claussen, 2009]. The lack of transparency in sustainable sourcing policies makes it nearly impossible for consumers to distinguish the good actors from the bad at the point of purchase. While it has been questioned if consumers are even interested in such information [Watson, 2010], there is the counterpoint that consumers may not have the ability to choose given a dearth of information. The main crux of symbolic strength is to lend support to multi-stakeholder processes, and pull that support when goals and benchmarks are not being met [Boström and Hallström, 2010].

Thus in summary, the opportunities for public aquariums to engage with the ornamental fish trade and improve its credibility include: 


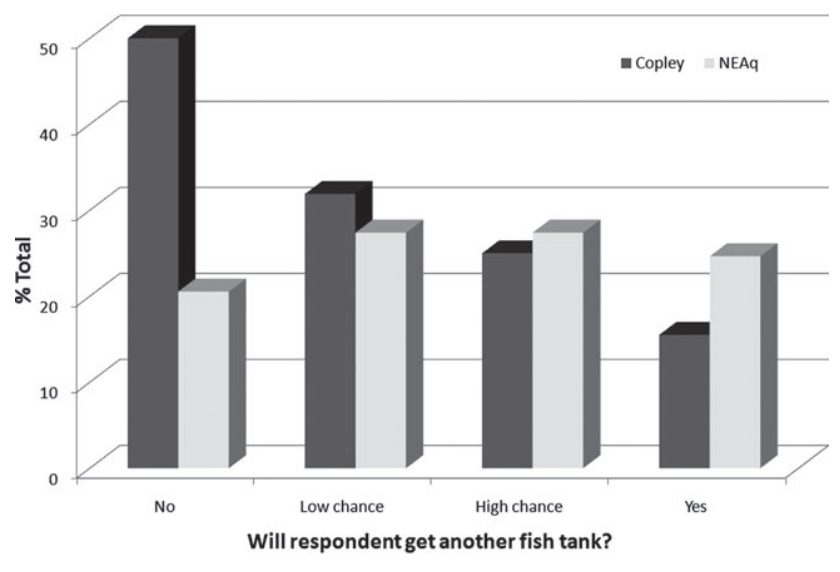

Fig. 2. Survey results for visitors to the New England Aquarium (light) and Copley shopping district (dark) who currently do not have fish tanks on their proclivity to start up a new fish tank.

- enact broad based cooperative strategies to help maintain rare and endangered species,

- source fishes appropriately and communicate this information to hobbyists,

- engage in multi-stakeholder advising of the industry, and limit support if agreed upon metrics are not met, and

- provide advisory services and transparency to wholesalers and retailers.

\section{ACQUIRING FISH}

Public aquariums have the opportunity to develop, practice, and convey appropriate and sustainable acquisition policies for ornamental fishes. These institutions need to be seen by their visiting public as leaders in fish procurement, and they need to help educate the public about appropriate fishes for home aquariums [Marliave et al., 1995], along with developing, testing, and helping the industry derive acquisition practices that can be implemented at a commercial scale [Andrews, 1990].

Both the North American based Association of Zoos and Aquariums (AZA) and the global World Association of Zoos and Aquariums (WAZA) address collection sustainability. The AZA [AZA, 2011] addresses collection ethics in their accreditation process (Box 1). WAZA recently developed a sustainability policy with the over-arching goal to "practice environmental sustainability, by showing by example how sustainability can be achieved and how social attitudes and behavior can be changed" [Penning et al., $2009, \mathrm{p}$ 42]. The ultimate goal is for these institutions to actively engage in and demonstrate to visitors how they are contributing to ecosystem-based conservation. Zoos and aquariums need to make sure sustainability policies go beyond merely maintaining populations for captive display, and a number of specific action items pertinent to acquiring animals are listed in Box 2.

The points addressed by both associations are all valid and overall will help to improve how fishes are acquired.
However, as stated, they lack a means for implementation and thus fall short in providing specific guidance for both public aquariums and the ornamental fish trade so that they may reach their full potential as unique and powerful tools for conservation. Both wild capture and captive breeding are suggested as ways to move forward [Thoney et al., 2003], but neither should be prioritized to the detriment of the other. Furthermore, as captive propagation is developed, it should not replace extractive fisheries that provide economic value for extant communities and ecosystems [Tlusty, 2002].

Here, a decision path is developed to determine if a species should be acquired from wild or aquaculture sources (or even be in the trade). This decision path is comprised of two questions: (1) should a species be in the trade? and (2) if so, should the species be produced via aquaculture or collected from wild fisheries? The enlightened self-interest of acquisition decisions of public aquariums should be transparent and justifiable from a sustainability perspective. It should also identify species that are not ideally suited for a novice home hobbyist, and this information should be effectively communicated to the public. While this decision path addresses species and production systems, it must be remembered that this is an idealized context. The ornamental fish trade has a long history with respect to species and sources, and the intent of this decision path is not to completely reformulate which fishes are in the trade and how they are produced within this industry, but to begin a serious discussion of these processes, and encourage reform where possible.

\section{Assessing Species That Should or Should Not Be in the Trade}

Although by no means government regulatory agencies, public aquariums can put forth a clear position on which species they advocate for home fish keeping based on animal welfare, environmental, and social considerations. The left side of the decision path for acquiring sustainable ornamental fishes and invertebrates for the pet trade is concerned with species that should be in the trade (Fig. 3). Appropriate species for the ornamental trade have been discussed for a number of years, in both peer reviewed and hobbyist literature, as well as on the Internet (i.e., Sustainable Aquarium Industry Association (www.saia-online.eu), see virtually any issue of Tropical Fish Hobbyist, Aquarium International, Amazonas or Coral Magazine). Overall, characteristics that make fishes unsuitable for the general ornamental fish trade include those that have the potential to become highly invasive in the destined market, are not legal for trade, or may be endangered, threatened, or protected. While this seems as an obvious point, the increase in Web-based sales may be exacerbating this activity (http://www.practicalfishkeeping. co.uk/content.php?sid=847). There is also illegal activity within countries of production, and Brazil, with one of the most restrictive export policies, is routinely subject to biopiracy [Chao and Petry, 2003]. In the United States, ownership 


\section{Tlusty et al.}

of piranhas is illegal in 25 states, but specimens have been observed in the wild in 13 states, with a breeding population being established in Florida (http:/www.angelfire.com/biz/ piranha038/Laws_and_Piranhas.html).

The next condition, being highly invasive and perceived as injurious, is a condition that with effort by industry could be proactively managed. Temperature tolerance is a major determinant of the probability of a species becoming established in a host ecosystem [Kolar and Lodge, 2002] and it is possible to determine the areas in which certain fishes could not establish breeding populations because winter temperatures are too low (e.g., USDA grow zones). This would be difficult to achieve as a large proportion of importers and production facilities are located in Florida and California. In the end, user, behavior cannot be assured, and may create improbabilities, such as tilapia becoming established in areas where they should not theoretically be able to be established (e.g., Illinois) [Nico and Schofield, 2010]. Finally, some fish have characteristics which make then unsuitable for entry level hobbyists (live feed, large sizes), but without specialized knowledge, the species should not be in the trade. Any such lists must be fluid and allow for advances in technologies and captive care as well as newly realized threats a species may pose. Given the trade restrictions on Convention on International Trade in Endangered Species (CITES) listed species, aquaculture does have an important function in providing such species to the hobby through designated breeding programs [Bartley, 2000]. But greater effort is needed to assure that CITES species do not enter the trade, or enter it legally [ $\mathrm{Ng}$ and Tan, 1997] with appropriate verification or certification of legality.

Box 1. AZA accreditation questions addressing practices of commercial collector [AZA 2011, pg 8]:

- Institutions dealing with collectors of aquatic animals must determine that the collection procedures used do not cause environmental damage (e.g., cyanide poisoning and reef blasting).

Explanation: The institution is encouraged to pursue and develop sustainable, environmentally friendly and responsible working relationships with all of its collection suppliers.

- Institutions dealing with commercial collectors must determine that the collectors are properly permitted to conduct legal collections of animals (including aquatic animals) from the wild.

Explanation: The institution must be proactive in ensuring that any commercial collectors utilized are properly permitted to conduct legal collections of animals from the wild.

Box 2. World Association of Zoos and Aquariums sustainability action items relevant to the sourcing of live display animals for display in public aquariums [Penning et al. 2009, pg 49].

- develop a sustainable and well-documented collection strategy including for the acquisition of wild aquatic animals and plants that encompasses the requirements of the Convention on Biodiversity (CBD), e.g. Marine Aquarium Council (MAC) certification;

- minimise any livestock losses in the course of acquisition through optimal collection, handling and transport techniques and excellent husbandry and veterinary care - and only use accredited suppliers who meet the same rigorous standards;

- develop sustainable collections of aquatic animals and plants through in-house breeding programmes;

- where possible and appropriate, increase inter-institution livestock transactions (acquisitions/ disposals), especially in terms of sourcing animals from successful breeding programmes;

- recognise sustainability as an important component of the educational responsibility of aquariums and focus on changing the attitudes, outlook and behaviours of aquarium visitors and, ultimately, the global population. 


\section{The Aquaculture: Wild Fish Dichotomy}

Once it has been established that a species is suitable for the trade, it then needs to be determined if specimens should be collected from the wild or produced in aquaculture [Tlusty, 2002]. Each production system has positive and negative attributes, and one goal of acquisition will be to maximize the positive production attributes of each species. The first questions of this decision assess if a wild fishery maintains ecosystems, cultural traditions, or economic benefits to local communities [Chao and Prang, 1997; Tlusty et al., 2008]. Next, one must determine (1) if wild collections destroy habitats, and conversely, (2) if aquaculture can be used in a ranching manner, or (3) if aquaculture can be linked to a decline of wild populations [Tlusty, 2002]. The salient feature of this decision is not to merely reduce impacts of the production of aquatic organisms, but rather pro-conservation interventions should be highlighted and embraced. Finally, there are questions if the species is domesticated or genetically modified [Lass, 2009], with genetically modified organism (GMO) fish requiring captive propagation.

The decisions about which species should or should not be in the trade, along with the means by which they are produced, are both questions which public aquariums should not only convey to their visitors [Marliave et al., 1995], but also practice in their own acquisition decisions. Debating which freshwater fishes should or should not be wild captured is a moot point. The overwhelming aquaculture production of these species is a result of the interplay of technology, logistics, demand, and knowledge. However, deconstructing the current state of affairs compared to an idyllic condition can provide information on what acquisition strategies could be implemented to improve the sustainability of the trade. The status quo should not be the implicit assumption that all species should be produced in aquaculture [Tlusty, 2002; Tlusty, 2004; Tlusty et al., 2008]. By assessing how production should be distributed, novel solutions become apparent and when such approaches are applied to fisheries, significant gains can be made while sacrificing little [Ban and Vincent, 2009]. Although freshwater fisheries provide a small percentage of the individuals within the current trade, those that still do exist provide positive examples [Chao and Petry, 2003; Tlusty et al., 2008], which can be used to drive development of sustainable fisheries practices in other regions [Raghavan et al., 2007], and ideally within marine environments [Reksodihardjo-Lilley and Lilley, 2007]. Public aquariums can interface with consumers to educate them about the environments from where their pets originate, as

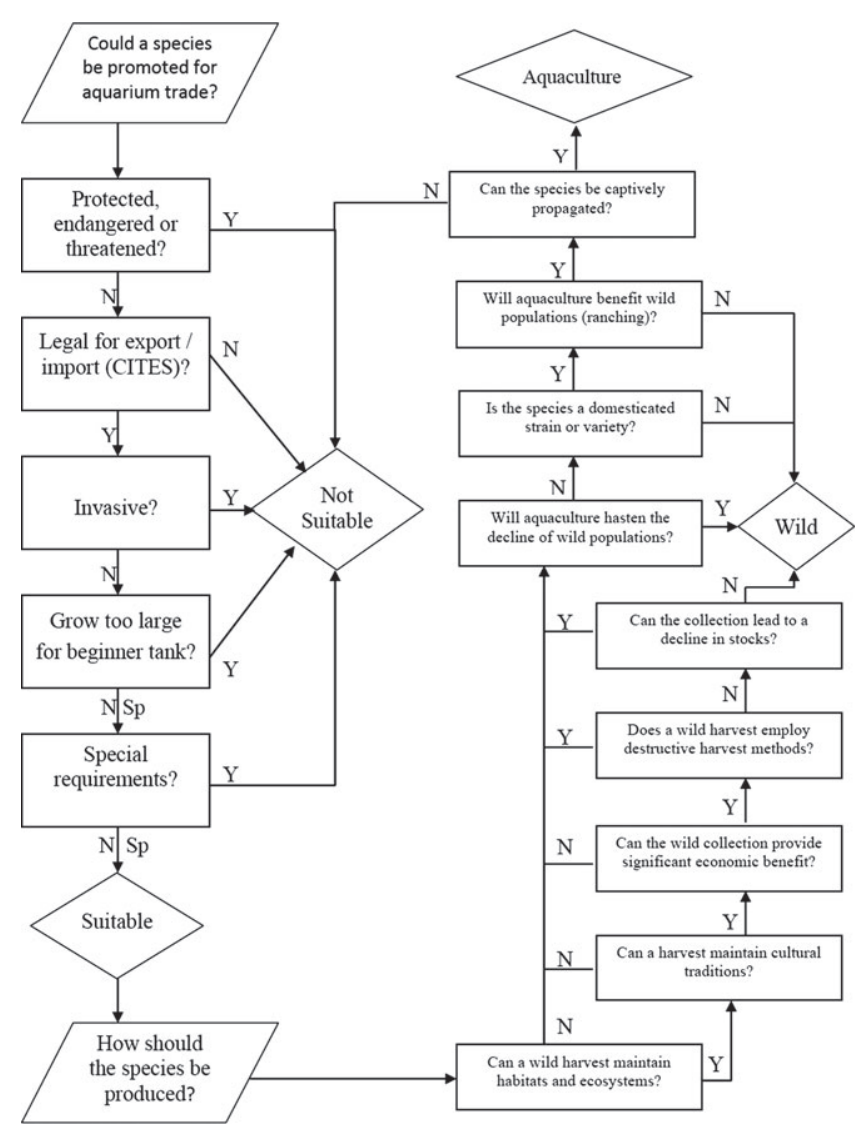

Fig. 3. Decision tree to determine which species are suitable for the ornamental fish trade (left side) and if those fish should be produced in wild fisheries or aquaculture (right side). Sp on the decision arrows indicates that specialists in the hobby have the ability to care for these animals. This is a theoretical construct, and does not account for how historical market forces have shaped current acquisitions. 
well as understand that sustainable collection of fishes is one strategy to maintain biodiversity both within the trade, as well as of the wildlife that remains in the species' natural habitat.

\section{Ensure Sustainable Production}

Within the global industry, it is important to increasingly acquire ornamental fishes produced with better practices. Therefore, some level of assurance (accreditation or certification) is needed to help create this culture of continual improvement. This level of assurance will help point-ofpurchase consumers to better understand their decisions, and will assist the retailers on the best sources of healthy fishes to stock for their customers.

While third-party certification programs for wild and aquaculture production would be ideal [Tlusty et al., 2006], the diffuse nature of wild fisheries [Watson, 2005] along with the implementation problems experienced by the Marine Aquarium Council [Alencastro, 2004; Bellamy and Winsby, 2008] create hurdles to further development of ornamental fish certification. In moving forward, public aquariums have the opportunity to be involved in the development of best practices or standards. The difficulty of certifying numerous small producers over a broad geographic area has in part been addressed by seafood programs that focus on artisanal fisheries and aquaculture clusters. The past difficulties of certification are not reason to entirely abandon any type of assurance scheme. It may be that initial efforts will have to be focused on best practices, and as they gain acceptance, can be moved into a more formal accreditation or certification scheme. Public aquariums have the opportunity to assist with the creation and oversight of these best practices.

\section{CONCLUSIONS}

The ornamental fish trade is large, although true magnitude of this industry is unknown. While survey data indicate that 79 million individual aquatic animals are held by hobbyists in the United States [AVMA, 2007], it is estimated that 190 million are imported annually [Smith et al., 2009]. Past reviews of the trade have focused mainly on threats to biodiversity from extraction and habitat destruction in the source countries and on the negative impacts of species invasions, yet, if properly administered, the aquarium trade has a unique potential for good. Some species have been saved from the brink of extinction because gene pools are kept thriving through the diligence of aquarists $[\mathrm{Ng}$ and Tan, 1997]. Sustainable supply-side practice, be it aquaculture or wild fisheries, can be a catalyst for habitat preservation, stewardship, poverty alleviation, and sustainable livelihoods and the safeguarding of threatened ecosystems that are otherwise unprotected. This is a unique opportunity for consumer-driven conservation in the wild which can promote species and habitat conservation. Informed consumers can promote widespread public appreciation for the world of water and understanding of what must be done to pass its wonders down intact to future generations. Inaction continues and potentially amplifies the damage currently inflicted by the trade, while a proactive stance can help to transform the large consumer base into a powerful agent for biodiversity conservation and human well being. Public aquariums can have conservation [Hutchins and Conway, 1995], educational and scientific [Falk and Dierking, 2010] impacts, as well as play a cooperative role in helping define more sustainable practices for the aquatic animal trade. Given that our survey data demonstrates that public aquariums are more frequented by visitors interested in keeping pet fish, public aquariums must take this leadership role seriously and provide measurable conservation outcomes. Furthermore, they should help ensure that their visitors are not responsible for the further demise of fisheries, destruction of habitats, and other potential negatives that occur from this growing and largely unregulated commercial trade.

The attitude of public aquariums regarding the ornamental fishes and invertebrate trade needs to be similar to their approach a decade ago on sustainable seafood. In addition, as collectors of wild harvested aquarium fishes and exhibitors of aquacultured fishes, public aquariums can educate millions of visitors about the benefits as well as the risks of the ornamental fish trade and conservation of the world's aquatic resources. Through leadership and through market-based initiatives, these institutions, working in conjunction with other environmental NGOs, professional societies, academia, and industry, can join together to transform the ornamental aquarium trade into a positive conservation force.

\section{ACKNOWLEDGMENTS}

E. Flynn assisted with survey data collection. We thank a number of people for discussions developing the ideas presented within. These in alphabetical order include B. Carlson, S. Kraus, D. Lass, M. Meyers, B. Ris, B. Spitzer, L. Squires, G. Stone, D. Thoney, T. Taranovski, J. Watters, and two anonymous reviewers. This paper is a contribution from the "Blueing the Aquarium Trade" initiative of the New England Aquarium and Conservation International.

\section{References}

Alencastro LA. 2004. Hobbyists' preferences for marine ornamental fish: a discrete choice analysis of source, price, guarantee and ecolabeling attributes. [Master's Thesis]. Gainesville, FL: University of Florida. p 110

Amos AM, Claussen JD. 2009. Certification as a conservation tool in the marine aquarium trade: challenges to effectiveness. Turnstone Consulting and Starling Resources Report. p 51.

Andrews C. 1990. The ornamental fish trade and fish conservation. J Fish Biol 37:53-59.

[AVMA] American Veterinary Medical Association. 2007. U.S. pet ownership and demographics sourcebook (2007 edition). Schaumburg, IL: American Veterinary Medical Association. p 159.

[AZA] Association of Zoos and Aquariums. 2010. Marine fish taxon advisory group regional collection plan. Baltimore, MD: AZA. p 123. 
[AZA] Association of Zoos and Aquariums. 2011. The accreditation standards and related policies 2011 edition. Silver Spring, MD: AZA. p 66.

Ban NC, Vincent ACJ. 2009. Beyond marine reserves: exploring the approach of selecting areas where fishing is permitted, rather than prohibited. PloS ONE 4:e6258.

Barker DG, Barker TM. 2009. Review: reducing the risks of the wildlife trade by K. F. Smith, M. Behrens, and L. M. Schloegel. Bull Chicago Herpetol Soc 44:96-97.

Bartley DM. 2000. Responsible ornamental fisheries. FAO Aquaculture News1 24:10-14.

Bellamy JJ, Winsby M. 2008. Mid-term review of the IFC/GEF Project "Marine Aquarium Market Transformation Initiative (MAMTI)." Project No. 506049. Washington, DC: Management. p 68.

Boström M, Hallström KT. 2010. NGO power in global social and environmental standardsetting. Global Environ Polit 10:36-59.

Chao NL, Petry P. 2003. Respect Brazil's 'Good List' Policy to avoid 'Biopiracy'. OFI J 43:14-16.

Chao NL, Prang G. 1997. Project Piaba-towards a sustainable ornamental fishery in the Amazon. Aquarium Sci Conserv 1:105-111.

Conde D, Flesness N, Colchero F, Jones O, Scheuerlein A. 2011. An emerging role of zoos to conserve biodiversity. Science 331:1390-1391.

Conway WG. 2010. Buying time for wild animals with zoos. Zoo Biol 29:1-8.

Costa-Pierce BA. 2010. Sustainable ecological aquaculture systems: the need for a new social contract for aquaculture development. Mar Technol Soc J 44:88-112.

Courtenay W, Stauffer J. 1990. The introduced fish problem and the aquarium fish industry. J W Aquac Soc 21:145-159.

Falk JH, Dierking LD. 2010. The 95 percent solution: school is not where most Americans learn most of their science. Am Sci 98:486-501.

Gusset M, Dick G. 2010. 'Building a future for wildlife'? Evaluating the contribution of the world zoo and aquarium community to in situ conservation. Int Zoo Yearbook 44:183-191.

Helfman GS. 2007. Fish conservation: a guide to understanding and restoring global aquatic biodiversity and fishery resources. Washington DC: Island Press. p 584.

Hemdal J. 2009. Aquarium fish: mortality rates of fishes in captivity. Adv Aquarist Online Mag 12(II):130-133.

Hueting R, Reijnders L. 2004. Broad sustainability contra sustainability: the proper construction of sustainability indicators. Ecol Econ 50:249260.

Hutchins M, Conway WG. 1995. Beyond Noah's Ark: the evolving role of modern zoological parks and aquariums in field conservation. Int Zoo Yearbook 34:117-130.

Hutchins M, Thompson SD. 2008. Zoo and aquarium research: priority setting for the coming decades. Zoo Biol 27:488-497.

Ikerd JE. 1999. Economics of enlightened self-interest. Annual Conference of Organization for Competitive Markets, Omaha, NE.

Jacquet JL, Pauly D. 2007. The rise of seafood awareness campaigns in an era of collapsing fisheries. Mar Policy 31:308-313.

Kolar CS, Lodge DM. 2002. Ecological predictions and risk assessment for alien fishes in North America. Science 298:1233-1236.

Koldewey HJ, Atkinson J, Debney A. 2009. Threatened species on the menu? Towards sustainable seafood use in zoos and aquariums. Int Zoo Yearbook 43:71-81.

Krishnakumar K, Raghavan R, Prasad G, Bijukumar A, Sekharan M, Pereira B, Ali A. 2009. When pets become pests-exotic aquarium fishes and biological invasions in Kerala, India. Curr Sci 97:4-6.

Kuhlman T, Farrington J. 2010. What is sustainability? Sustainability $2: 3436-3448$.

Lass D. 2009. Great fish for kids to keep. Aquarium Fish Int Dec:34-38.

Marliave J, Mulligan M, Andrews C. 1995. Advisory logos for pet-trade fishes in public aquariums. Int Zoo Yearbook 34:101-104.

McClenachan L, Cooper AB, Carpenter KE, Dulvy NK. 2011. Extinction risk and bottlenecks in the conservation of charismatic marine species. Conserv Lett 5:73-80

Miller B, Conway W, Reading RP, Wemmer C, Wildt D, Kleiman D, Monfort S, Rabinowitz A, Armstrong B, Hutchins M. 2004. Evaluating the conservation mission of zoos, aquariums, botanical gardens, and natural history museums. Conserv Biol 18:86-93.

$\mathrm{Ng}$ P, Tan H. 1997. Freshwater fishes of Southeast Asia: potential for the aquarium fish trade and conservation issues. Aquarium Sci Conserv 1:179-190.
Nico LG, Schofield PJ. 2010. Oreochromis niloticus. Available at: http:// nas.er.usgs.gov/queries/factsheet.aspx?SpeciesID=468 (accessed 1 October 2011). RevisionDate: 6/7/2007: USGS Nonindigenous Aquatic Species Database.

Penning M, Reid G, Koldewey H, Dick G, Andrews B, Arai K, Garratt P, Gendron S, Lange J, Tanner K, Tonge S, Van den Sande P, Warmolts D, Gibson C. 2009. Turning the tide - a global aquarium strategy for conservation and sustainability. Bern, Switzerland: World Association of Zoos and Aquariums. p 78

Ploeg A. 2010. The OFI Code of Conduct. Ornamental Fish Int. www.ofish. org/welcome/oficode-of-conduct (accessed 30 March 2012).

Prosek J. 2010. Beautiful friendship. Natl Geogr Mag 217:120-124.

Raghavan R, Tlusty M, Prasad G, Pereira B, Ali A, Sujarittanonta L. 2007. Should endemic and threatened freshwater ornamental fishes of Kerala part of the Western Ghats biodiversity hotspot be captive bred for international trade? Curr Sci 93:1211-1213.

Raven P. 2004. Botanical gardens and the 21st century. P Calif Acad Sci 55:275-282.

Reksodihardjo-Lilley G, Lilley R. 2007. Towards a sustainable marine aquarium trade: an Indonesian perspective. SPC Live Reef Fish Inform Bull 17:11-19.

Rhyne A, Rotjan R, Bruckner A, Tlusty M. 2009a. Crawling to collapse: ecologically unsound ornamental invertebrate fisheries. PloS One 4:e8413.

Rhyne AL, Tlusty M, Bourque B, Scott T. 2009. Defining the role of pubic aquariums in providing a source of larvae: The Roger Williams University \& New England Aquarium affiliation results in the first successful rearing of the queen triggerfish Balistes vetula. September 2009. Veracruz, Mexico: World Aquaculture.

Rhyne AL, Tlusty MF, Schofield PJ, Kaufman L, Morris JS, Bruckner A. 2012. Revealing the Appetite of the Marine Aquarium Fish Trade: the Volume and Biodiversity of fish imported into the United States. PloS ONE DOI: 10.1371/journal.pone.0035808.

Saunders T, McGovern L, Kerry JF. 1993. The bottom line of green is black: strategies for creating profitable and environmentally sound businesses. San Francisco, CA: Harper Collins. p 282

Schmidt C, Kunzmann A. 2005. Post-harvest mortality in the marine aquarium trade: a case study of an Indonesian export facility. SPC Live Reef Fish Inform Bull 13:3-12.

Smith KF, Behrens M, Schloegel LM, Marano N, Burgiel S, Daszak P. 2009. Reducing the risks of the wildlife trade. Science 324:594-595.

Smith KF, Guégan J-F. 2010. Changing geographic distributions of human pathogens. Annu Rev Ecol Evol Systematics 41:231-250.

Tamaru C, Ako H. 2000. Using commercial feeds for the culture of freshwater ornamental fishes in Hawaii. In: Tamaru C, Tamaru C, McVey J, Ikuta $\mathrm{K}$, editors. Spawning and maturation of aquatic species, UJNR Technical Report No 28. Honolulu, HI: University of Hawaii Sea Grant College Program. p 109-120.

Thoney DA, Warmolts DI, Andrews C. 2003. Acquisition of fishes and aquatic invertebrates for zoological collections. Is there a future? Zoo Biol 22:519-527.

Tissot BN, Hallacher LE. 2003. Effects of aquarium collectors on coral reef fishes in Kona, Hawaii. Conserv Biol 17:1759-1768.

Tlusty MF. 2002. The benefits and risks of aquacultural production for the aquarium trade. Aquaculture 205:203-219.

Tlusty MF. 2004. Small scale of production does not automatically mean small scale of impact. OFI J 46:6-9.

Tlusty MF. 2012. Environmental improvement of seafood through certification and ecolabelling: theory and analysis. Fish and Fisheries 13:1-13.

Tlusty MF, Dowd S, Halle BOV. 2006. Yes fish need to be certified-a reply to Watson. OFI J 51:49-52.

Tlusty MF, Dowd S, Raghavan P. 2008. Saving forests through the fisheries-ornamental fisheries as a means to avoid deforestation. OFI J 56:21-25.

Tlusty MF, Lagueux K. 2009. Isolines as a new tool to assess the energy costs of the production and distribution of multiple sources of seafood. J Cleaner Prod 17:408-415.

USDA National Agricultural Statistics Service. 2005. Table 13 ornamental fish production and sales by species, by state and United States: 2005 and 1998. Census of Agriculture. Washington DC: Government Printing Office. p 49-52.

Wabnitz C, Taylor M, Green E, Razak T. 2003. From ocean to aquarium. Cambridge, UK: UNEP-WCMC. p 64. 


\section{Tlusty et al.}

Ward TJ, Phillips BF. 2008. Seafood ecolabelling: principles and practice. Oxford, UK: Wiley-Blackwell. p 472.

Watson I. 2005. Do fish need to be certified? OFI J 49:22-25.

Watson I. 2010. Green fish, does the customer care? OFI J 64:16-19.

Wildes M. 2003. The role of public aquaria in aquatic conservation and research [Master's thesis]. Boston, MA: Northeastern University. p 101
Wintner R. 2010. The dark hobby; can we stop the devastating impact of home aquaria on reefs worldwide? Available at: http://www.seashepherd.de/newsand-media/editorial-xs 100821-1.html. Downloaded on August 1, 2011.

World Commission On Environment and Development. 1987. Our common future. New York: Oxford University Press. p 400.

Zajicek P, Hardin S, Watson C. 2009. A Florida marine ornamental pathway risk analysis. Rev Fisheries Sci 17:156-169. 